\title{
Detecting Good Neighbor Nodes and Finding Reliable Routing Path Based on AODV Protocol
}

\author{
Supriya Bamane ${ }^{1}$, Rajesh Singh ${ }^{2}$ \\ ${ }^{I}$ (Student Dept. of Computer Engg. University of Pune Sinhgad Institute of Technology, Lonavala, India) \\ ${ }_{2}^{2}$ (Dept. of Computer Engg. University of Pune Sinhgad Institute of Technology, Lonavala, India)
}

\begin{abstract}
Wireless operations allow services, such as long-range communications, that are impossible or impractical to implement with the use of wires. It is supported by well-liked technique known as Adhoc Protocol [1]. The term is commonly used in the telecommunications industry to refer to telecommunications systems e.g. radio transmitters and receivers, remote controls etc. which use some form of energy e.g. radio waves, acoustic energy, etc. to transfer information without the use of wires. ${ }^{[1]}$ Information is transferred in this manner over both short and long distances.In this, routes may be detached due to lively movement of nodes. So route assortment and topology grouping is not easy and demanding issue. This type of networks is more vulnerable to both internal and external attacks due to presence of wicked neighbour nodes[1][2s. Paper see the sights new method using AODV protocol to find out good neighbour node and finding reliable path according to their signal strength, flow capacity relative position of node in network.
\end{abstract}

Keywords: AODV routing protocol, ad-hoc network, signal Strength, flow capacity, relative position of node Routing Table.

\section{INTRODUCTION}

An Ad Hoc Network (MANET) is a wireless network consisting of mobile nodes, which can communicate with each other without any infrastructure support. In these networks, nodes typically cooperate with each other, by forwarding packets for nodes which are not in the communication range of the source node. Typically, routing protocols are classified according to the route discovery philosophy, into either reactive or proactive. Reactive protocols are on-demand. Route-discovery mechanisms are initiated only when a packet is available for transmission, and no route is available. On the other hand, proactive protocols are table-driven. Routes are precomputed and stored in a table, so that route will be available whenever a packet is available for transmission.

Our work is based on link stability in wireless networks. Link stability is unique to wireless network. Link stability refers to the ability of a link to survive for certain duration. The higher the link stability, the longer is the link duration. The stability of a link depends on how long two nodes, which form that link, remain as neighbours. Two nodes are neighbours when they remain within each other's communication range, or the signal strength is above certain threshold. Mobility causes link breakage and leads to route recovery. Transport layer performance degrades as a result of packet loss and trigger congestion control mechanism. A more stable link should therefore be preferred. However, routing algorithms that are based only on link stability have either been shown to exhibit little improvement over hop-count based algorithm or the improvement comes when link lifetime can be accurately predicted. A crucial issue with stability based routing algorithm is that much longer routes can be obtained compare to hop-count based routing.

For the last decade, many researches had been performed in mobile ad hoc networks (MANETs), especially in routing protocol of Ad hoc On-demand Distance Vector (AODV) for the optimization or better performance. Many people expect that someday there will be a robust and reliable protocol due to the nature and characteristics of MANETs that always change, decentralized, self-configured, and had no infrastructure to manage. In the early 2000s, researchers focused on the development of basic functions or services of the AODV protocol, such as shared channel, route discovery, and dynamic nodes. The purpose of their studies was to manage an ad hoc network topology that always change and answer the problem of disconnected route (route error) caused by the level of mobility ad hoc node that cannot be predicted.

A major drawback of all existing ad hoc routing protocols is that they do not have provisions for conveying the energy and priority and/or quality of a path during route setup. Hence they cannot balance the load on different routes therefore we have taken Priority and Power into consideration. Also, both proactive and reactive protocols chose a route based on the metric, the smallest number of hops to the destination. But it may not be the most significant route. It may cause the packet drop rate, packet end-to-end delay, or routing overhead to be increased.

Conventional on-demand routing protocols such as AODV and DSR are energy-unaware. Routing is done based on shortest path, the cost metric either considers number of hops or end-to-end delay at the time 
when route is established. The protocols do not proactively modify routes until they break. If nodes are energyconstrained, such metrics may have adverse effect on the network lifetime on the whole. Since recharging or replacing the battery is not feasible in most of the ad hoc network applications, it is imperative to study and design routing protocols which are able to conserve node energy to prevent premature death.

\section{RELATED WORK}

Table 1:Literature Survey

\begin{tabular}{|c|c|c|c|c|}
\hline $\begin{array}{l}\text { Sr. } \\
\text { No }\end{array}$ & Paper Title & Author(s) & Publish In & Technique used \\
\hline 1 & $\begin{array}{c}\text { AODV Based } \\
\text { Improved Method } \\
\text { for Detecting Good } \\
\text { Neighbor Nodes }\end{array}$ & $\begin{array}{l}\text { Supriya Bamane } \\
\text { Rajesh Singh }\end{array}$ & $\begin{array}{l}\text { International Journal } \\
\text { of Emerging } \\
\text { Technology and } \\
\text { Advanced } \\
\text { Engineering (ISSN } \\
\text { 2250-2459, ISO } \\
\text { 9001:2008 Certified } \\
\text { Journal, Volume 3, } \\
\text { Issue 7, July-2013) }\end{array}$ & $\begin{array}{l}\text { The system is divided into five phases:- } \\
\text { a) Phase A: Initialize the nodes } \\
\text { Initialize all node position and update data in } \\
\text { neighbour routing table and initialize node } \\
\text { transmission range and network transmission } \\
\text { range. } \\
\text { b) Phase B: Broadcast Hello Message to all } \\
\text { neighbour nodes } \\
\text { c) Phase C: Calculate Time and Compare NTr } \\
\text { with TTrN } \\
\text { After getting reply hello message, calculate time } \\
\text { and according to that time compare NTr with } \\
\text { TTrN. If NTr is high than TTrN decrease NTr and } \\
\text { when NTr is less than TTrN then calculate signal } \\
\text { strength. } \\
\text { d) Phase D: Calculate Signal Strength and flow } \\
\text { capacity of Node } \\
\text { e) Phase E: Update Routing Table } \\
\text { Update neighbour node routing table according to } \\
\text { signal strength, flow capacity of node and relative } \\
\text { position of node. }\end{array}$ \\
\hline 2 & $\begin{array}{c}\text { Improved } \\
\text { Neighbor } \\
\text { Detection } \\
\text { Algorithm for } \\
\text { AODV Routing } \\
\text { Protocol }\end{array}$ & $\begin{array}{l}\text { SrdjanKrco and } \\
\text { Marina Dupcinov }\end{array}$ & $\begin{array}{c}\text { IEEE } \\
\text { Communications } \\
\text { letters, vol. 7, no. 12, } \\
\text { December } 2003\end{array}$ & $\begin{array}{l}\text { 1. If an AODV message (Hello, RREQ, RREP, } \\
\text { etc.) is received from a node that has no entry in } \\
\text { the routing table, the SNR of the link measured } \\
\text { when the packet was received must be higher than } \\
\text { a certain upper limit (defined as } \\
\text { "THRESHOLD"), otherwise the AODV message } \\
\text { is ignored; } \\
\text { 2. If an AODV message (Hello, RREQ, RREP, } \\
\text { etc.) is } \\
\text { received from a node, which is a neighbor in the } \\
\text { routing } \\
\text { table, the SNR must be higher than a certain } \\
\text { lower limit (defined as "THRESHOLD"- } \\
\text { "DELTA_SNR"), otherwise the AODV message } \\
\text { is ignored. }\end{array}$ \\
\hline 3 & $\begin{array}{c}\text { The Routing } \\
\text { Protocol of AODV } \\
\text { Based on Link } \\
\text { Failure Prediction }\end{array}$ & $\begin{array}{c}\text { Qing Li1, Cong Liu1, } \\
\text { Han-hong Jiang2 }\end{array}$ & $\begin{array}{c}\text { ICSP2008 } \\
\text { Proceedings }\end{array}$ & $\begin{array}{l}\text { In the process of data transmission, the node } \\
\text { estimate the distance between itself and the } \\
\text { sending node through the intensity of the received } \\
\text { packet signal, and estimate the relative velocity } \\
\text { between the sending node and itself through the } \\
\text { time difference of the neighboring received data } \\
\text { and the intensity of packet signal. }\end{array}$ \\
\hline 4 & $\begin{array}{c}\text { An Enhancement } \\
\text { of Fault- } \\
\text { TolerantRouting } \\
\text { Protocol for } \\
\text { Wireless Sensor } \\
\text { Network }\end{array}$ & $\begin{array}{c}\text { Che-Aron. } \\
\text { Al-Khateeb. Anwar, } \\
\text { F. }\end{array}$ & $\begin{array}{c}\text { International } \\
\text { Conference on } \\
\text { Computer and } \\
\text { Communication } \\
\text { Engineering (ICCCE } \\
\text { 2010), 11-13 May } \\
2010\end{array}$ & $\begin{array}{l}\text { Apply a backup route technique by creating a } \\
\text { backup path for every node on a main path of data } \\
\text { transmission. When a node gets failure to deliver } \\
\text { a data packet through the main path, it } \\
\text { immediately utilizes its backup route to become a } \\
\text { new main path for the next coming data packet } \\
\text { delivery to reduce a number of data packets } \\
\text { dropped and to maintain the continuity of data } \\
\text { packet transmission in presence of some faults } \\
\text { (node or link failures). }\end{array}$ \\
\hline 5 & $\begin{array}{c}\text { An Improved } \\
\text { AODV Protocol } \\
\text { with Lower Route } \\
\text { Cost and Smaller } \\
\text { Delay - } \\
\text { PWAODV }\end{array}$ & $\begin{array}{c}\text { Wang Ningning } \\
\text { Cao Yewen }\end{array}$ & $\begin{array}{l}\text { IEEE } \\
\text { Fourth International } \\
\text { Conference on } \\
\text { Intelligent } \\
\text { Computation } \\
\text { Technology and } \\
\text { Automation } \\
2011\end{array}$ & $\begin{array}{l}\text { Piggyback and Weighted neighbor stability Ad } \\
\text { hoc On-demand Distance Vector routing) } \\
\text { protocol with lower route cost and smaller delay } \\
\text { is presented. PWAODV the NCR path will be } \\
\text { copied in the routing table when the intermediate } \\
\text { node receives the RREQ firstly. Then, for the } \\
\text { same RREQreceived later, just update the routing } \\
\text { table and reverse pathonly if the item of NCR } \\
\text { path is greater. In this way, the RREQreaches the }\end{array}$ \\
\hline
\end{tabular}




\begin{tabular}{|c|c|c|c|c|}
\hline & & & $\begin{array}{l}\text { destination node and the final path will be } \\
\text { themost stable one. Next, the destination node } \\
\text { will reply aRREP and reply again only if the later } \\
\text { received RREQ has greater sequence } \\
\text { or } \\
\text { equivalent one but greater NCR path. }\end{array}$ \\
\hline 6 & $\begin{array}{c}\text { RE-AODV: An } \\
\text { Enhanced Routing } \\
\text { Algorithm for } \\
\text { QoS Support in } \\
\text { Wireless Ad-Hoc } \\
\text { Sensor Networks }\end{array}$ & $\begin{array}{l}\text { M.Usha.S.Jayabharath } \\
\text { iR.S.D.Wahida Banu3 }\end{array}$ & $\begin{array}{c}\text { IEEE-International } \\
\text { Conference on Recent } \\
\text { Trends in Information } \\
\text { Technology, ICRTIT } \\
2011\end{array}$ & $\begin{array}{l}\text { Step 1: Discover the neighbor node by sending } \\
\text { hello packets along with route information. } \\
\text { Step 2: If no route is available, send the hello } \\
\text { packet alone. } \\
\text { Step 3: When RREQ is received, check the local } \\
\text { route table to know whether any neighbor with } \\
\text { route to destination exists. } \\
\text { Step 4: If so, send RREP. If not, broadcast RREQ. }\end{array}$ \\
\hline
\end{tabular}

A Mobility Tracking Model for Wireless Ad Hoc Networks

Proc. Sixth IEEE Int'l Symp. World of Wireless Mobile and Multimedia Networks (WWMM), pp. 286-292, June 2005.

- In an ad hoc wireless network, connectivity is determined by the physical locations and transmission ranges of the mobile units. In effect, user mobility causes the topology of an ad hoc network to change dynamically over time, which complicates the important tasks of routing and flow control.

- propose a novel scheme for tracking the mobility of users in a wireless ad hoc network. Mobile nodes track their positions using pilot signal strength measurements from neighboring nodes.

\section{Exploiting Path Diversity in the Link Layer in Wireless Ad Hoc Networks}

IEEE J. Selected Areas in Comm., vol. 23, no. 1, pp. 28-39, Jan. 2005.

- The goal is to exploit path diversity in the link layer by choosing the best next hop to forward packets when multiple next hop choices are available. Such choices can come from a multipath routing protocol, for example. This technique can reduce transmission retries and packet drop probabilities in the face of channel fading.

- The mechanism at the link layer that forwards packets to the best suitable next hop link to enable efficient packet forwarding on a multi-hop route. This mechanism is dependent on the availability of multiple next hops, which could be computed by a multipath routing protocol.

\section{LocationingIn Distributed Ad-Hocwireless Sensor Networks}

Proc. Wireless Comm. and Networking Conf.(WCNC), pp. 1790-1795, March 2003.

- Wireless sensing nodes rely heavily on the ability to establish position information. The algorithms presented herein rely on range measurements between pairs of nodes and the a priori coordinates of sparsely located anchor nodes. Clusters of nodes surrounding anchor nodes cooperatively establish confident position estimates through assumptions, checks, and iterative refinements.

- Ad Hoc Routing Protocols:

A number of routing protocols have been suggested for ad-hoc networks. These protocols can be classified into two main categories:

Table driven routing protocols.

Source initiated on demand routing protocols.

- Table Driven Routing Protocols:

Table-driven routing protocols attempt to maintain consistent, up-to-date routing information from each node to every other node in the network. These protocols require each node to maintain one or more tables to store routing information, and they respond to changes in network topology by propagating updates throughout the network in order to maintain a consistent network view. The areas in which they differ are the number of necessary routing-related tables and the methods by which changes in network structure are broadcast.

- Source Initiated On Demand Routing:

A different approach from table-driven routing is source-initiated on demand routing. This type of routing creates routes only when desired by the source node. When a node requires a route to a destination, it initiates a route discovery process within the network. This process is completed once a route is found or all possible route permutations have been examined. Once a route has been established, it is maintained by a route maintenance procedure until either the destination becomes inaccessible along every path from the source or until the route is no longer desired. 


\section{Programmer's DESIGN}

Initially when to start the system that time system contain two actor one is server and second is node this are present in network. So when to start the system that time server is get started first and at the server side to maintain all information about each node those are present in network that information is nothing but the routing table information. In routing table to store the node information that is node IP address, sequence number, node signal string, flow capacity, relative position of node, etc.

So when to start the system that time at server side to find out number of node those are present in network at that time. After finding that number of node creates the topology between the nodes. To create topology using two methods that is manually and automatically. After creating topology at server end that topology reflect at every node side. At node end display topology on screen in that node end display the present node and there neighbour node structure. Then to start the communication process.

In communication process initially all nodes maintain their own transmission range in this method. Transmission range (NTr) of each node present in the network is compared with the total transmission of network (TTrN). Then broadcast request hello message to all neighbour nodes except misbehaviour node to identified misbehaviour node using server side information and each node routing table information. In that to identified misbehaviour node to check the packet drop ratio(PDR) of each node if PDR is high means more than 3 then declare that node is misbehaviour node and do not consider that node in father communication. After broadcasting hello message to receive hello message reply from neighbour nodes, It calculates time to reach the hello message from neighbour nodes to originalAfter getting $\mathrm{NTr}$ it is compare with $\mathrm{TTrN}$. If $\mathrm{NTr}$ is higher than the TTrN, then adjust the energy of this node accordingly and calculate the signal strength. If threshold value observed is higher then judge the relative position of node and set timer accordingly. Check the flow capacity of particular node and in that case if packet delivery ratio (PDR) is okay then store node address in routing table and declare that node as a good node. By figure 1 find out good neighbour node step by step. Good neighbor node can be found out using steps shown in figure 3 The proposed system is divided into six phases:-

a) Phase A: Create Topology at server side

In this phase at server side to first find out the number of node that are present in network. After finding the number of nodes to create network topology by using two methods that are:-

1. Using system design:-

In this method when server want to perform the communication that time server get no. of nodes present in network and using that node randomly create topology between that present nodes.

2. Using manually:-

In this method if created topology is not in proper format so that time to give choice and create proper format topology.

b) Phase B: Initialize the nodes

This phase initialize all node position and update data in neighbour routing table and initialize node transmission range and network transmission range.

c) Phase C: Broadcast Hello Message to all neighbour nodes

In this phase, when source node wants to create route then source node it broadcasts hello message to all neighbour nodes and receives reply hello message from neighbour node. But when source node send the message at that time they only send message to normal node not misbehaviour node.

d) Phase D: Calculate Time and Compare NTr with TTrN

After getting reply hello message, calculate time and according to that time compare NTr with TTrN. If $\mathrm{NTr}$ is high than TTrN decrease NTr and when NTr is less than TTrN then calculate signal strength.

e) Phase E: Calculate Signal Strength and flow capacity of Node

Using equation 1 to find out signal strength of node, judge relative position of node .If it is high then judge flow capacity of node. If PDR (packet delivery ratio) is ok then mark that node as good node.

f) Phase F: Update Routing Table

Update neighbour node routing table according to signal strength, flow capacity of node and relative position of node

\section{Mathematical Model}

In proposed system Node signal strength is calculate by using equation 1, 


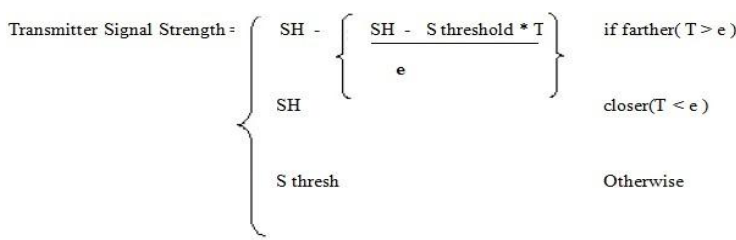

SH :- Signal Strength $\quad T$ :- Time Period Between 2 successive Packets

(1)

In that Equation $\mathrm{SH}$ is signal strength of hello message and Time between two successive hello message is $\mathrm{T}$ and $\mathrm{e}$ is the link connection between two node to calculate signal strength of particular node.

Then flow capacity of node $\mathrm{i}$ is calculated by using equation 2 ,

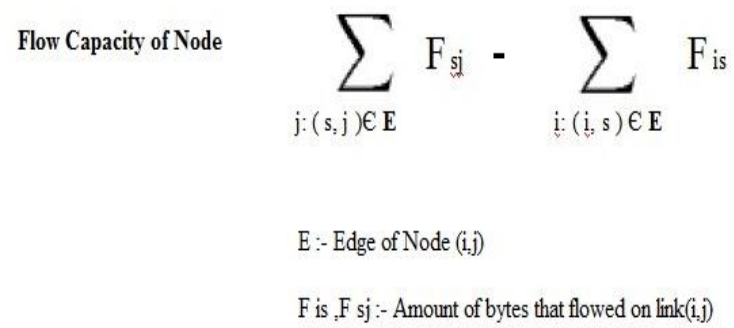

V. RESUlts AND DiscuSSION

\section{Server Side Screen Shot}

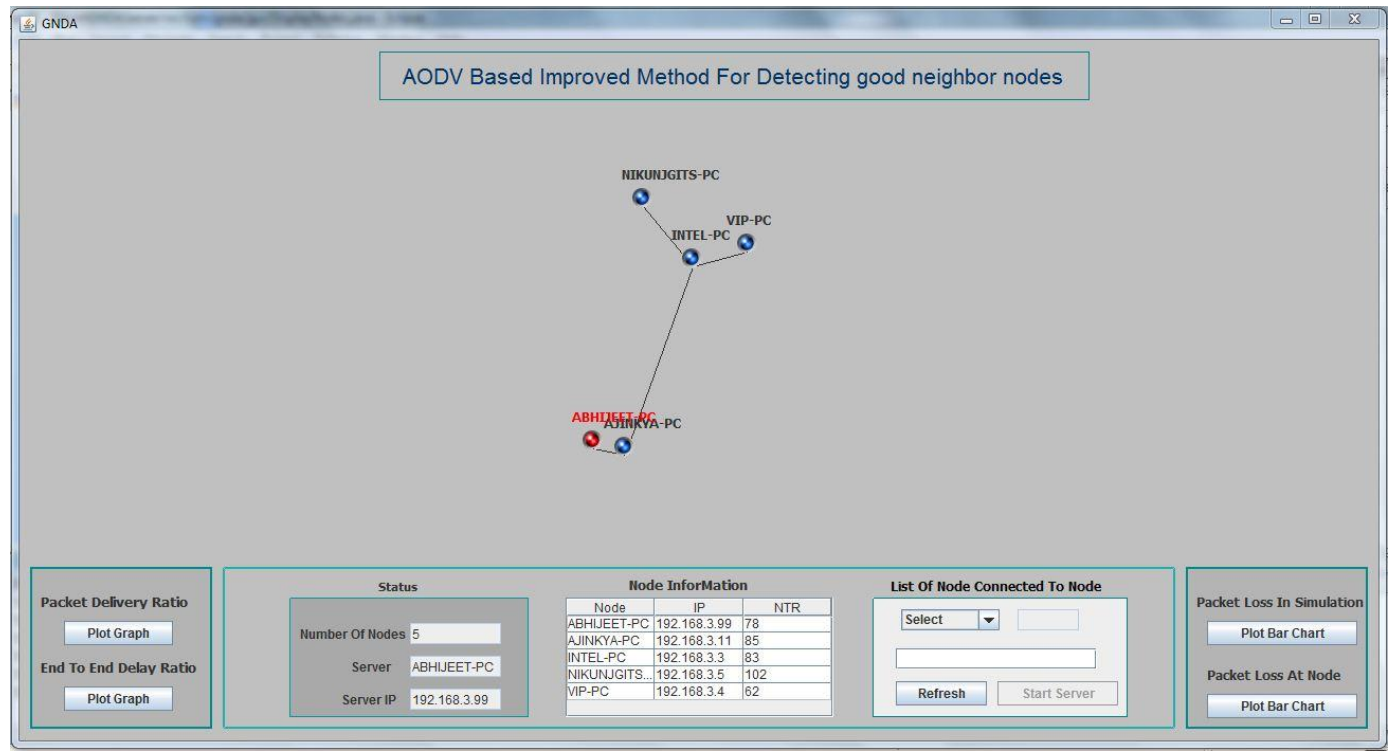

Fig. 1: Server Side Screen Shot

Figure 1 shows that server side screen shot, in that they show the information about all node those are present in network, there ip address, NTR, server node that ip address and tab to create graph for different result.

\section{Server Side Routing Table before Path Creation}

\begin{tabular}{|c|c|c|c|c|c|c|c|}
\hline id & node & nts & ip & sh & Tolatsend & Totakeceive & misbehavecnt \\
\hline 1 & ABHINEET.PC & 78 & 192168.3 .99 & 0 & 0 & 0 & 0 \\
\hline 2 & ANINKYA.PC & 85 & 192.168 .3 .11 & 0 & 0 & 0 & 0 \\
\hline 3 & INTEL-PC & 83 & 192168.3 .3 & 0 & 0 & 0 & 0 \\
\hline 4 & NIKUNJGGITSPCC & 102 & 192168.3 .5 & 0 & 0 & 0 & 0 \\
\hline 5 & VIP.PC & 62 & 192168.3 .4 & 0 & 0 & 0 & 0 \\
\hline
\end{tabular}

Table 2 shows the Server side routing table. In That when to start the system that time initially routing table parameter (signal string, Total send packet, Total received packet, misbehave count ) are set as zero, and when path is create that time that value are update. 


\section{Server Side Routing Table after Path Creation}

\begin{tabular}{|c|c|c|c|c|c|c|c|}
\hline id & node & nir & ip & sh & Tolatsend & Totalreceive & misbehavecrk \\
\hline 1 & ABHIJEET-PC & 78 & 192.168 .3 .99 & 0 & 0 & 0 & 0 \\
\hline 2 & AJINKYA.PC & 85 & 192.168 .3 .11 & 3152.3478260 . & 4 & 3 & 0 \\
\hline 3 & INTEL.PC & 83 & 192.168 .3 .3 & 5516.730964467 & 8 & 7 & 1 \\
\hline 4 & NIKUNJGITS.PC & 102 & 192.168 .3 .5 & 0 & 3 & 3 & 0 \\
\hline 5 & YIP.PC & 62 & 192.168 .3 .4 & 0 & 2 & 2 & 0 \\
\hline
\end{tabular}

Table 3 shows the Server side routing table. In That when path is create that time routing table parameter (signal string, Total send packet, Total received packet, misbehave count ) value are update.

Node Side Screen Shot

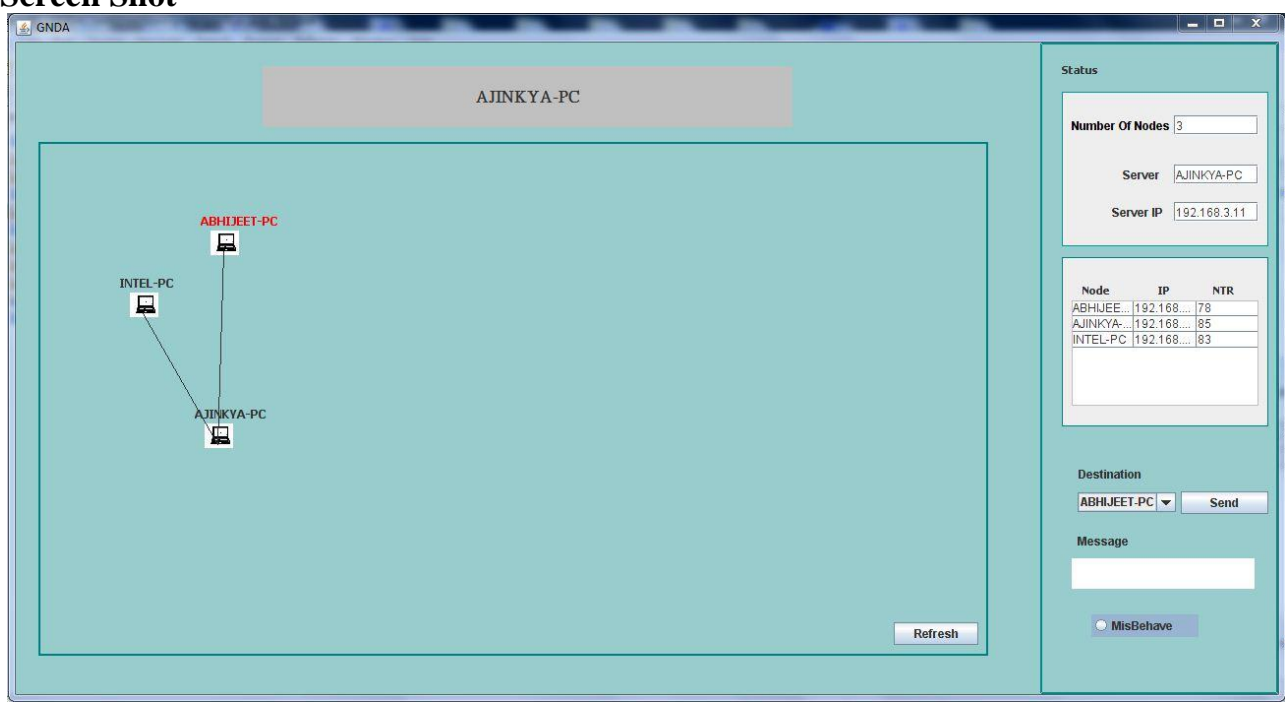

Fig.2: Node Side Screen Shot

Figure 2 show Node side screen shot in that they show link between node and there neighbour node in graphical view and all neighbour node information in table format.

\section{Node Side Screen Shot with Message}

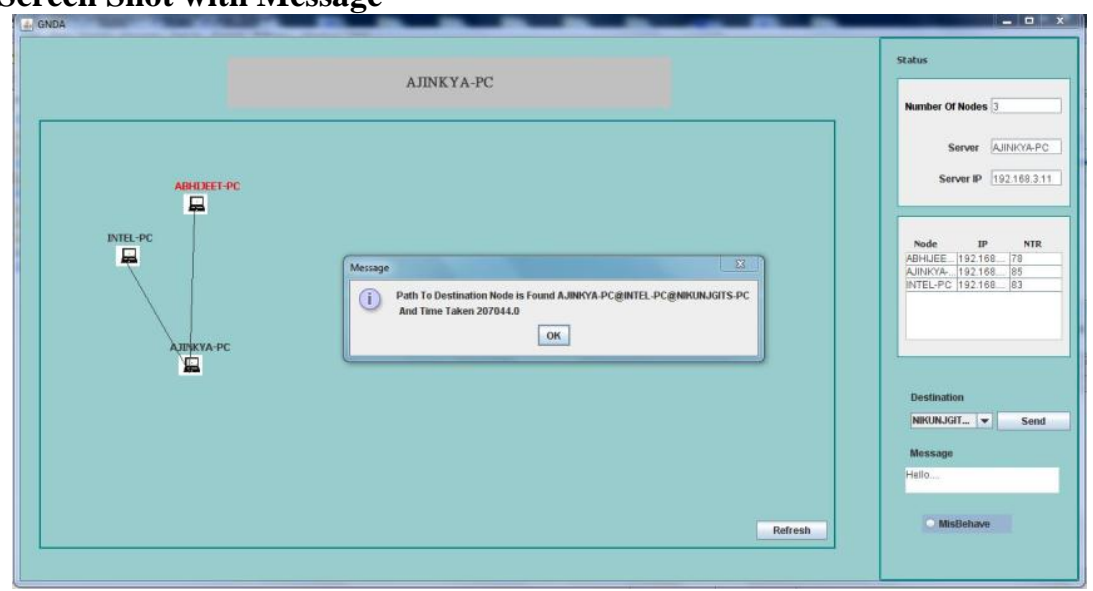

Fig. 3: Node Side Screen Shot with Message

Node Side Routing Table before Path Creation

Table 4: Node Side Routing Table before Path Creation

$\begin{array}{llllr}\text { id node } & \text { path } & \text { ip } & \text { nit misbehave } & \text { packetDroped } \\ 1 \text { ABHIJEET.PC } & \text { AJINKYA.PCHABHIJEET.PC } & 192.168 .3 .9978 \text { lalse } & 0 \\ 2 \text { AJINKYA.PC } & \text { AJINKYA.PCHAJNNKYA.PC } & 192.168 .3 .1185 \text { lase } & 0 \\ 3 \text { INTEL.PC } & \text { AJINKYA.PCHINTEL.PC } & 192.168 .3 .383 \text { lalse } & 0\end{array}$


Table 4 shows the Node side routing table. In That when to start the system that time initially routing table parameter (node, ip address, ntr, misbehave status and pdr ) are set as zero, and when topology is create that time that value are update.

\section{Node Side Routing Table after Path Creation}

Table 5: Node Side Routing Table after Path Creation

\begin{tabular}{|c|c|c|c|c|c|}
\hline id & node & path & ip & ntt misbehave & packetDroped \\
\hline 1 & ABHWEET-PC & ANINKYA.PCHABHIJEET.PC & $192.168 .3,99$ & 78 false & 0 \\
\hline 2 & ANINKYA.PC & ANINKYA.PCHANJINKYA.PC & 192168.3 .11 & 85 false & 0 \\
\hline 3 & INTEL-PC & ANINKYA.PCHINTEL.PC & 192168.3 .3 & 83 true & 1 \\
\hline
\end{tabular}

\section{End To End Delay in Communication}

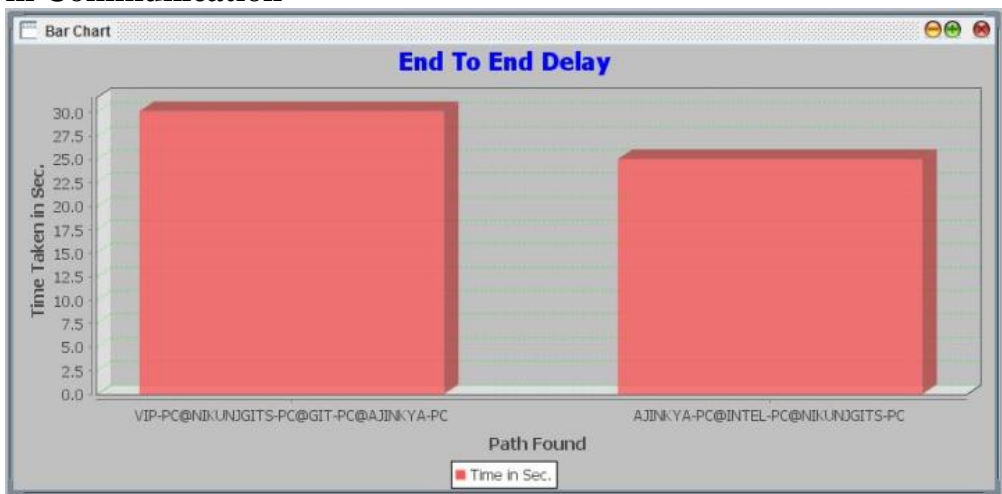

Fig. 4: End to End Delay Chart

Figure 4 show the end-to-end delay is the average time between data packets sent out from the sources and received at the destination. The delay can be denoted with respect to number of nodes and mobility rate. As the mobility rate increases the end-to-end delay is always increases because the network topology changes more frequently. So selecting good node and create route to decrease end to end delay.

\section{Misbehave Count}

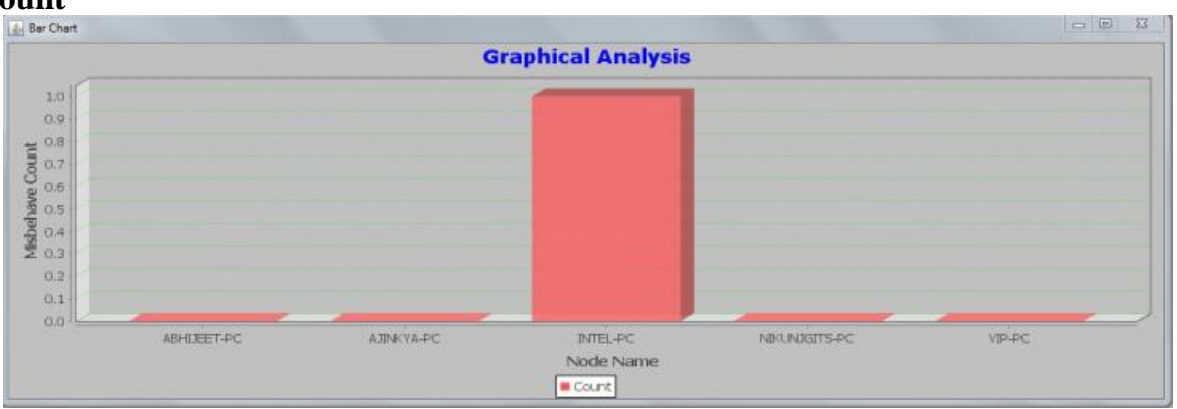

Fig. 5: Misbehave Count of Each Nodes

Figure 5 show the misbehave count chart in that chart those node declared as a misbehave node, do consider that node in next any path creation step.to find out misbehave node using server routing table information otherwise those node drop packet more than three time, declare that node as misbehave node.

\section{Packet Delivery Ratio}

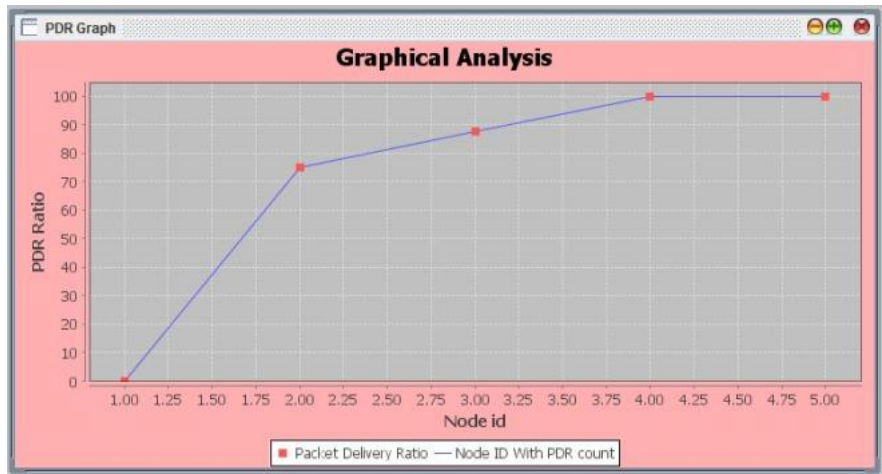

Fig. 6: Packet Delivery Ratio Chart 
Figure 6 show Packet delivery ratio is the ratio of the data packets received at the destination to the data packets sent out from source. The delivery ratio can be denoted by mobility rate. As the mobility rate increases, the delivery ratio always decreases.

- Complexity Computation:-

In proposed method performance of each node is calculated and analyzed individually. Evaluation is done by increasing node number and network size, But proposed method have some limitation .If number of node is increasing or network size is increasing then cost of project increases.

- Energy Consumption :-

From the comparative study it is observed that energy consumption by using good neighbor node is more than the AODV protocol. For transferring data between source to destination node, select only good neighbor node Good nodes have maximum signal strength and flow capacity. So use that node to transfer data fast.

According to [1] AODV protocol with 6 no of nodes the information successfully delivery percentage is 83.61 and with 10 no of nodes it is 84.65 . According to proposed methodology with 6 no of nodes the successfully delivery percentage is 99.73 and with 10 no of nodes it is 94.72 . The complexity of proposed methodology depend on no of nodes present in network i.e. $\mathrm{O}(\mathrm{N})$.

\section{CONCLUSION}

While designing routing protocol security issues are ignored in an ad - hoc network. Route failures, bad node present in network this are important issues face when to perform communication. In proposed approach Store all information related to good nodes in routing table and update information time to time. This will improve network presentation. Simulation results show that our proposed solution improves network immovability and communication. In future, we may need to classify good nodes from bad nodes from protection point of view and so packet drop ratio will be reduced.

\section{REFERENCES}

[1] Supriya Bamane .Rajesh Singh. AODV Based Improved Method for Detecting Good Neighbor Nodes International Journal of Emerging Technology and Advanced Engineering (ISSN 2250-2459, ISO 9001:2008 Certified Journal, Volume 3, Issue 7, July 2013)

[2] Prof. M.N. Hoda and Umang Singh, GNDA: Detecting Good Neighbour Nodes in Ad-hoc Routing Protocol 2011 Second International Conference on Emerging Applications of Information Technology, IEEE.

[3] C. E. Perkins and E. M. Royer, âA.Ad hoc on demand distance vector(AODV) routing,âAI Internet- Draft, draft-ietf-manet-aodv02.txt, Nov. 1998

[4] C.Siva Ram Murthy and B.S.Manoj,A.Ad hoc Wireless Networks AI,Pearson 2005.ISBN 81-297- 0945- 7 Sridhar K N and Mun Choon Chan ,A.Stability and Hop-Count based Approach for Route Computation in MANET,AI, 0-7803-9428- 3/05/ 2005 IEEE.

[5] Youngrag Kim, Shuhrat Dehkanov, Heejoo Park, Jaeil Kim, Chonggun Kim, âA.The Number of Necessary Nodes for Ad Hoc Network Areas AI, 2007 IEEE Asia-Pacific Services Computing Conference

[6] [ Srdjan Krco and Marina Dupcinov, Improved Neighbor Detection Algorithm for AODV Routing Protocol IEEE COMMUNICATIONS LETTERS, VOL. 7, NO. 12, DECEMBER 2003.

[7] Qing Li, Cong Liu, Hang Hong Jiang, The Routing Protocol of AODV Based on Link Failure Prediction ICSP2008 Proceedings, 9781-4244-2179- 4/08/25.00 2008 IEEE

[8] M. Usha, S. Jayabharathi, Wahida Banu R, REAODV: An enhanced routing algorithm for QoS Support in Wireless Ad-hoc Sensor Networks ,2011, IEEE International conference on Recent trends in Information Technology.

[9] Che-Aron, Al-Khateeb, Anwar, An Enhancement of Fault-Tolerant routing protocol for wireless sensor network, 2010, IEEE International conference on computer and communication engineering.

[10] Wang N, Cao Yewen, An Improved AODV protocol with lower route cost and smaller delay, 2011, IEEE fourth international conference on intelligent computation technology and automation.

[11] P. Gupta and P. R. Kumar,The Capacity of Wireless Networks, IEEE Transactions on Information Theory, 46(2): 388-404,20007 